Assessing Investment and Longevity Risks within Immediate Annuities

Daniel Bauer, Frederik Weber

Discussion Paper 2007-07

July 2007

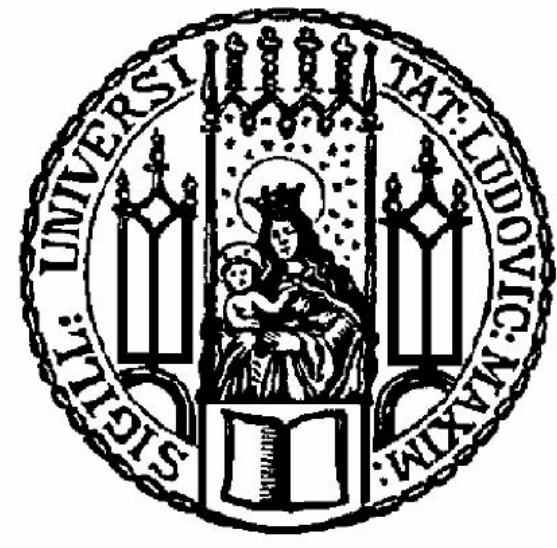

LMU

LUDWIG-MAXIMILIANS-UNIVERSITÄT MÜNCHEN

MUNICH SCHOOL OF MANAGEMENT

Online at http://epub.ub.uni-muenchen.de/ 


\title{
Assessing Investment and Longevity Risks within Immediate Annuities
}

\author{
Daniel Bauer \\ DFG Research Training Group 1100, Ulm University \\ Helmholtzstraße 18, 89069 Ulm, Germany \\ E-mail: daniel.bauer@uni-ulm.de \\ Frederik Weber* \\ Institute for Risk and Insurance Management, Ludwig-Maximilians-University Munich \\ Schackstraße 4, 80539 München, Germany \\ E-mail: fweber@lmu.de
}

\begin{abstract}
Life annuities provide a guaranteed income for the remainder of the recipient's lifetime, and therefore, annuitization presents an important option when choosing an adequate investment strategy for the retirement ages. While there are numerous research articles studying annuities from a pensioner's point of view, thus far there have been few contributions considering annuities from the provider's perspective. In particular, to date there are no surveys of the general risks within annuity books.

The present paper aims at filling this gap: Using a simulation framework, it provides a long-term analysis of the risks within annuity books. In particular, the joint impact of mortality risks and investment risks as well as their respective influences on the insurer's financial situation are studied.

The key finding is that, under the model specifications and using annuity data from the United Kingdom, the risk premium charged for aggregate mortality risk seems to be very large relative to its characteristics. Possible reasons as well as economic implications are provided, and potential caveats are discussed.
\end{abstract}

Keywords: Annuities, Lee-Carter Model, Longevity Risk 993882 


\section{Introduction}

Life annuities provide a guaranteed income for the remainder of the recipient's lifetime; therefore, annuitization represents an important option when choosing an adequate investment strategy for the retirement ages. Yaari (1965) showed that in a deterministic financial economy and in the absence of bequest motives, expected utility maximizers will annuitize their entire wealth. The same result was recently confirmed by Davidoff et al. (2005) in a more general market setting. However, although the current problems with state-run pay as you go schemes in many countries and the shift from defined benefit to defined contribution plans should increase the demand for annuities, empirical studies show that the proportion of retirees choosing to annuitize their wealth is rather small. In economic literature, this phenomenon is commonly referred to as the "annuity puzzle".

Possible explanations for this peculiarity may be the consumption limitations or, more precisely, the suboptimal consumption profile due to constant annuity pay-outs (see, for example, Brown (2001) or Milevsky et al. (2006)), demographic risk (Schulze and Post (2006)), or the existence of bequest motives. Another reason could be that annuities are overpriced or, more specifically, are conceived to be overpriced by investors: Typically, yields on long-term debt are used to calculate the "actuarially fair price" of an annuity, even though the rate of return on, for example, the insurer's capital may be substantially higher (see James and Song (2001)). Therefore, even if annuities are priced "actuarially fair" - we still have to specify exactly what this means - their prices may still be regarded as too high by investors.

In Mitchell et al. (1999), the actuarially fair price of an annuity is defined to be the expected present value, where they use current yields of treasury and corporate bonds as well as cohort mortality tables that are adjusted for selection effects 1 to determine interest and mortality rates, respectively. They find that in the US in 1995 the average annuity policy generally delivers pay-outs of less than 91 cents per unit of annuity premium. According to the authors, this "transaction cost" is primarily due to expenses, profit margins, and contingency funds. However, the question of whether this discount is adequate is not addressed.

Similar results are found in Finkelstein and Poterba (2002) for the United Kingdom (UK) with the same notion of actuarially fair priced annuities. Here, adverse selection effects are even more pronounced and explain about $65 \%$ of the difference between the pay-outs associated with private annuities and the pay-outs that would be available if these products were actuarially fair. However, the remaining difference between the actual and the fair value per unit of annuity premium, which amounts to between 5 and 14 cents for different types of annuity contracts and different cohorts, is also not analyzed further.

Murthi et al. (1999) come to similar conclusions. However, they note that annuitization costs of about $5 \%$ of the account value are very small in comparison to costs during the accumulation phase of a personal pension plan, where over $40 \%$ of an individual account's value is consumed by various charges and fees. They provide possible explanations for their discoveries, but also several caveats: For instance, their results are quite sensitive to mortality assumptions, and they are focussing on the mean of the money's worth of an annuity without considering its distribution.

These annuitization costs, i.e. the positive difference between actuarially fair and market-observed annuity prices, arise endogenously in the model presented in a paper by Van de Ven and Weale (2006). In their two period overlapping generation

\footnotetext{
${ }^{1}$ In general, mortality rates for the overall population exceed those for individual annuity purchasers when comparing them within the same year and cohort.
} 
model, they consider the effect of aggregate longevity uncertainty on annuity rates. Within an equilibrium framework they show that - given risk-averse preferences - annuities are sold at a discount for aggregate mortality risk. The value of this discount is very sensitive to both, the changes in the risk aversion parameter and the level of uncertainty regarding the future lifetime.

All-in-all, there tends to be an accordance among empirical and theoretical approaches that annuities are not fairly priced, i.e. they include a "transaction cost", which at least partially consists of contingency funds and, thus, can be interpreted as a risk discount. However, it is not clear whether this discount is adequate, and it is unclear whether this risk discount is majorly influenced by investment or longevity risk, that is the risk that future mortality trends differ from those which are anticipated.

While all of the above mentioned articles look at annuities from a pensioner's point of view, we will take a different approach by considering the annuity business from the provider's position. From an insurer's perspective, selling annuities is similar to assuming a short position in a forward contract on the survival of the annuitants within the insurer's portfolio. However, this position cannot be hedged as, thus far, there are no appropriate securities ${ }^{2}$ But, similar to classical portfolio selection problems, we can then analyze the risk-return profile of the insurer's position.

So far, there have been few contributions assessing the risk within annuities, and according to Dowd et al. (2006), insurance companies have a general problem assessing the magnitude of the financial risk implied by their mortality exposure. Using the two-factor stochastic mortality model from Cairns et al. (2006b), Dowd et al. (2006) give a "blueprint" which estimates risk measures for any mortality-dependent risk and provides four illustrative types of mortality dependent financial positions, including an insurer's annuity book hedged by a hypothetical longevity bond similar to the one announced (but never emitted) by the European Investment Bank and BNP Paribas in November 2004 . However, their analysis is rather geared towards the general study of mortality contingent positions and does not provide a survey of the risks within an annuity book in general.

The present paper aims at filling this gap: It provides a long-term analysis of the risks of a book of annuities and, in particular, provides insights on how influential mortality risks and investment risks are, respectively; furthermore, the implications of this analysis are discussed. More specifically, we focus on the question of whether annuities are priced appropriately regarding the inherent risk as well as if there is a need for instruments hedging longevity risk.

In order to assess the risks within annuities, adequate forecast models are needed for both, the evolution of mortality and the investment risk. The latter, i.e. modeling the evolution of financial assets, is a well-studied problem with many available models. For forecasting the evolution of mortality, on the other hand, the list of appropriate models is relatively shorter. One of the most prominent models is the so-called Lee-Carter model (see Lee and Carter (1992)) with its various extensions (see, for example, Lee (2000), Brouhns et al. (2002), or Renshaw and Haberman (2003)). See Cairns et al. (2006a) for a detailed overview and a categorization of stochastic mortality models.

The rest of the present paper is organized as follows: In Section 2, we introduce

\footnotetext{
${ }^{2}$ An exception would be so-called longevity bonds, i.e. financial securities with payoffs depending on the survival of a certain cohort or population (see Blake et al. (2006) and references therein for a detailed description). However, to the authors' knowledge, no such securities are available on the market at this point.
} 
the annuity book and the underlying models. Particularly, we introduce models for the different financial asset classes which will be considered as well as the mortality model supporting our considerations. Section 3 describes our simulation framework. In addition to the general framework, we describe the data used to calibrate the models and the underlying annuity prices. Our results are then presented in Section 4, with Section [5 concluding. Finally, in Section 6, we summarize, discuss the limitations of our results, and provide an outlook on our future research.

\section{Modelling the Risks within an Annuity Book}

According to Dowd et al. (2006), in order to assess the magnitude of the financial risk implied by an insurer's mortality exposure, the key ingredients are a stochastic model of aggregate mortality, a selection of financial risk measures, and a simulation framework. In order to assess the dimension of the financial risk implied by an insurer's annuity book, we further need a stochastic model for the insurer's assets.

In this section, after introducing the contract and the "risk" in Subsection 2.1 we will discuss and provide our choice of asset models and mortality model in Subsections 2.2 and 2.3, respectively.

\subsection{The Annuity Book}

An annuity is an insurance contract providing payments for the remaining lifetime of the insured, i.e. it is contingent on the insured's survival. Annuities are offered in various designs, as deferred or immediate annuities, index linked or fixed, with or without guarantee periods, etc. We focus on the simplest kind possible, namely a fixed single premium immediate annuity (SPIA) without any guarantee period, which is also one of the predominant types of contracts, especially in the UK market. The annuity market can be divided into open market options and compulsory purchase annuities. While according to Finkelstein and Poterba (2002), the compulsory market is considerably larger than the voluntary market, we will focus on prices for the open market option, since it also allows compulsory annuitants to purchase their annuity from life insurance companies other than the one in which their funds have been accumulating. Thus, the structure of our annuity contract is quite simple: At time zero, the annuitant pays a certain single premium, say $P$, to the annuity provider. In return (neglecting credit risk) the annuitant obtains a payment of $U$ units every period conditional on his or her survival.

Therefore, assuming an initial expense of $\phi$ units, the policyholder's account value $A$ at time 1 in case of survival of the insured person will be

$$
A_{1}=(P-\phi)\left(1+\delta_{1}\right)-U 1_{\{\tau>1\}},
$$

where $\delta_{t}$ is the charge-adjusted return on the asset process governing the policy reserve fund from time $t-1$ to time $t$, and $\tau$ is the time of death of the recipient. Similarly, the account value at time $t$ - given the insured's survival until $t-1$ - is given by

$$
A_{t}=A_{t-1}\left(1+\delta_{t}\right)-U 1_{\{\tau>t\}} .
$$

Assuming that the insurer's portfolio of policies is large enough to neglect unsystematic mortality risk $k^{3}$ and considering $x_{0}$-year old males at time 0 , equation (1) can be transformed to express the reserve per unit annuity (i.e. $U=1$ ) at time $t$ as

$$
R_{t}=R_{t-1}\left(1+\delta_{t}\right)-{ }_{t} p_{x_{0}}
$$

\footnotetext{
${ }^{3}$ Here, unsystematic mortality risk corresponds to that portion of the risk that can be diversified by the law of large numbers. See Biffis et al. (2005) for a classification of risks affecting insurance securities.
} 
where ${ }_{t} p_{x_{0}}$ denotes the (realized) proportion of the population of $x_{0}$ years olds at time 0 , who are still alive at time $t$, i.e. who survived $t$ periods from time 0 to time $t$. It is worth noting that $R_{t}$ is not known prior to time $t$ and, thus, is a random variable as both $\delta_{t}$ and ${ }_{t} p_{x_{0}}$ are random variables that are $\mathcal{F}_{t}$-measurable. 4

If $\omega$ denotes the limiting age, i.e. if survival beyond age $\omega$ is not possible, there are no payments after time $T=\left(\omega-x_{0}\right)$. Thus, the remaining surplus $R_{T}$ characterizes the profitability regarding this particular book of annuities from the insurer's point of view:

- If $R_{T}<0$, the reserves have not been sufficient to cover the insurer's liabilities. The resulting shortfall has to be financed using other funds.

- If $R_{T} \geq 0$, there have been enough reserves to settle all claims, and the remaining surplus remains with the insurer as a profit.

Therefore, in order to assess the risk of a book of immediate annuities, it is sufficient to analyze the properties of the random variable $R_{T}$, which depends on the evolution of both the insurer's assets and liabilities.

\subsection{Modelling the Insurer's Assets}

We assume that at time zero, the insurer invests in three different types of assets: bonds, a savings account $B$, and a well-diversified stock portfolio $S$. We further assume that non-defaultable zero coupon bonds for any maturity $t$ exist and that they are available for a price of $p(0, t)$ at time 0.5 Thus, the amount invested in a bond with maturity $t$ accrues a constant interest rate over the period $[0, t]$, while returns on funds invested in $B$ and $S$ yield a stochastic return corresponding to the evolution of the interest rate and the stock portfolio, respectively. Hence, we need to make assumptions about the dynamics of $B$ and $S$. While numerous models with different levels of sophistication are available, we decided to use rather simple, but yet common specifications

The savings account $B$ is assumed to evolve corresponding to the differential equation

$$
d B_{t}=r_{t} d t
$$

where $r=\left\{r_{t}\right\}_{t>0}$ is the nominal short-rate of interest, which is modelled by a mean reverting square root process

$$
d r_{t}=\kappa\left(\gamma-r_{t}\right) d t+\sigma_{r} \sqrt{r_{t}} d W_{t}
$$

i.e. we assume the well-known Cox-Ingersoll-Ross (CIR) model for the evolution of the short rate (see Cox et al. (1985) for details). Here, $\kappa, \gamma$, and $\sigma_{r}$ are some positive constants and $W$ is a standard one-dimensional Brownian motion. Furthermore, we model the stock portfolio $S$ by a geometric Brownian motion, i.e. we let

$$
d S_{t}=S_{t}\left(\mu d t+\sigma_{S} d Z_{t}\right)
$$

where again, $\mu$ and $\sigma_{S}$ are some positive constants, and $Z$ again is a one dimensional standard Wiener process independent of $W$. In particular, we assume independence of the asset and the short rate process.

\footnotetext{
${ }^{4}$ As usual, we fix a complete filtered probability space $\left(\Omega, \mathcal{F}, \mathbf{F}=(\mathcal{F})_{t}, P\right)$ for our consideration, where the filtration $\mathbf{F}$ describes the information flow and is assumed to satisfy the usual conditions (see, e.g., Bingham and Kiesel (2003)).

${ }^{5}$ Since the assumption that bonds are available for all maturities and in particular that ultralong bonds do exist is rather unrealistic, it has carefully to be taken into account when analyzing the results.
} 
Having specified the underlying processes, we need to assume certain allocation strategies in order to obtain the evolution of the returns on the reserve $\delta$ from equation (2). We will consider two strategies:

1. The insurer does not try to hedge the liabilities and invests the entire funds into the savings account and the stock portfolio at fixed proportions $(1-\alpha)$ and $\alpha$, respectively, and we also assume that the portfolio is continuously rebalanced. Thus, $\alpha$ describes the stock proportion within the insurer's asset portfolio.

2. The insurer tries to hedge the liabilities by buying ${ }_{t} \hat{p}_{x_{0}}$ bonds with maturity $t$ for $t=1, \cdots, T$, where ${ }_{t} \hat{p}_{x_{0}}$ denotes the best estimate of his liabilities ${ }_{t} p_{x_{0}}$ at time $t$. The remainder of the reserve is invested into the portfolio from strategy 1. If the payoff from a $t$-bond exceeds the liabilities, the excess amount will also be transferred to this portfolio. Similarly, if the bond payoff is insufficient, funds from the portfolio are used to fulfill the insurer's obligations. Thus, it is sufficient to simulate the short-rate and the stock portfolio as bond prices are only needed at time zero when market prices are available.

These two asset strategies are both somewhat extreme: In the first opportunistic strategy, the insurer does not try to match his assets to his liabilities at all, whereas in the second, assets are matched to liabilities as well as possible at time zero. However, the considered strategies do not allow for adjustments based on the information at time $t$, but are $\mathcal{F}_{0}$ measurable. Thus, when continuously rebalancing the portfolio according to the information available, the insurer could even improve the hedge in strategy 2.

Even though empirical investment strategies will be somewhere in between, we believe that these two scenarios will provide adequate insights on the actual distribution of $R_{T}$, and as the existence of ultra-long bonds is not an issue within strategy 1 , this rather unrealistic assumption does not present a general limitation. However, there are some caveats: When funds are not sufficient to cover the liabilities, i.e. if the reserve $R_{\tau}$ becomes negative for some $\tau$, these strategies imply that the insurer will finance the shortfall by borrowing against a portfolio consisting of stocks and a savings account rather than just borrowing money at the prevailing interest rate, which is a rather unrealistic assumption. Hence, negative final reserve accounts have to be treated with care with respect to the amount of the shortfall, but not the fact that they are negative. This should also be considered when analyzing the results.

\subsection{Modelling the Insurer's Liabilities}

According to equation (2), it is sufficient to model ${ }_{t} p_{x_{0}}$ appropriately. Recently, it has become clear that mortality improvements behave in an unpredictable manner (for an assessment of future mortality trends, see, e.g., Currie et al. (2004)). Therefore, it is not sufficient to use estimates from prevailing mortality tables, but the stochasticity has to be taken into account.

So far, several stochastic mortality models have been proposed - for a detailed overview and a categorization see Cairns et al. (2006a). One of the most prominent stochastic models for mortality was proposed by Lee and Carter (1992, henceforth LC). This approach has rapidly gained acceptance not only in academia but also among practitioners, which may partly be due to its relative simplicity.

In the LC model logarithmic central death rates $m_{x, t}$ for a life aged $x$ at discrete times $t$, or during years $[t, t+1)$, are assumed to follow the equation

$$
\ln m_{x, t}=a_{x}+b_{x} \kappa_{t}+\varepsilon_{x, t}
$$


where $a_{x}$ and $b_{x}$ are age-dependent parameters, $\kappa_{t}$ is a so-called time index 6 independent of age - and $\varepsilon_{x, t}$ is the error term incorporating residuals with $\varepsilon_{x, t} \sim$ $N\left(0, \sigma_{\varepsilon}^{2}\right)$.

When they originally proposed this model, Lee and Carter used the Singular Value Decomposition (SVD) technique for a least-squares estimation of $a_{x}, b_{x}$, and $\kappa_{t}$ by

$$
\left(\ln m_{x, t}-\hat{a}_{x}\right)_{x, t}=\hat{b}_{x} \hat{\kappa}_{t}+\varepsilon_{x, t}=U D V^{T}=\sum_{i=1}^{r} u_{i} d_{i} v_{i} .
$$

The matrices $U$ and $V$ denote the left and right singular matrices, respectively, and $D$ is the diagonal matrix containing the singular values $d_{i}$ in a descending order. Here $r=\operatorname{rank}\left(U D V^{T}\right)$, and $u_{i}$ and $v_{i}$ are the left-hand and right-hand singular vectors, respectively. For a more detailed description of the original estimation procedure and interpretation of the model parameters, refer to e.g. Lee and Carter (1992), Lee (2000) or Brouhns et al. (2002).

A number of authors have pointed out that the first term of the sum in (6), $u_{1} d_{1} v_{1}$, is in many cases able to explain a large portion of the aggregate variation of the left-hand expression. For instance, Tuljapurkar et al. (2000) showed that $\frac{d_{1}^{2}}{\sum_{i=1}^{r} d_{i}^{2}} \geq 0.94$ for a number of low-mortality countries. This may also be due to the fact that the singular values $d_{i}$ are ordered. Following previous analyses we will only consider the first term of the sum to represent the expression $\hat{b}_{x} \hat{\kappa}_{t}$ while the remainder $\sum_{i=2}^{r} u_{i} d_{i} v_{i}$ will be treated as the error term $\varepsilon_{x, t}$. Furthermore, we assumed the simple restrictions $\sum_{t} \hat{\kappa}_{t}=0$ and $\sum_{x} \hat{\beta}_{x}=1$ which were originally used by LC as well in order to ensure uniqueness of the solution.

Despite its relative simplicity the LC model in its original form has a number of shortcomings, one of which is the assumption that error terms are homoscedastic, i.e. $\varepsilon_{x, t} \sim N\left(0, \sigma_{\varepsilon}^{2}\right) \forall x, t$. Alho (2000) - among others - pointed out that this assumption is somewhat unrealistic since in a number of cases residuals actually showed significant variation with respect to the age $x$.

Among a large number of extensions and propositions for improvement and to overcome the shortcomings of the original LC model is a very interesting approach presented e.g. by Brouhns et al. (2002). They resort to the notion that the number of deaths among people aged $x$ in a given time interval $[t, t+1), d_{x, t}$, can be regarded as a Poisson counting process, and this idea in turn goes back to Brillinger (1986). The assumption, however, implies that error terms are heteroscedastic, i.e. $\operatorname{Var}\left(\varepsilon_{x, t}\right)$ may vary by age $x$, which a a lot more realistic. Another advantage is the fact that parameters (which have virtually the same interpretation as in the LC model) can be obtained iteratively as maximum likelihood estimators using an algorithm developed by Goodman (1979).

Not only because this model can be fitted easier than the original LC model but also due to the more realistic assumptions we will use this alternative approach for our further analysis of mortality. Henceforth it will be denoted by PML ("Poisson maximum likelihood").

It remains to add that LC originally included a reestimation $\hat{\hat{\kappa}}_{t}$ of the time-index $\hat{\kappa}_{t}$ in their model to avoid discrepancies between actual, observed numbers of deaths and those predicted when using the "first-step" estimations $\hat{\kappa}_{t}$. We renounced this step following the notion of Brouhns et al. (2002) who pointed out that in the context of the PML approach this reestimation is not necessary.

${ }^{6}$ The parameter $\kappa_{t}$ is different from the one introduced in (3). 
As will be detailed in Subsection 3.1 we considered different sets of mortality data. However the fitting procedure is independent of the specific nature of the underlying data set, and we shall briefly describe our approach.

Using the actual number of deaths $\left(d_{x, t}\right)$ and exposure to risk $\left(E_{x, t}\right)$ for persons aged $x$ at time $[t, t+1)$ (henceforth "in year $\mathrm{t}$ "), we applied the iterative fitting procedure proposed by Brouhns et al. (2002) to the data for all relevant ages and years (cf. Subsection 3.1 for details). Thus we obtained the parameter estimates $\hat{a}_{x}, \hat{b}_{x}$, and $\hat{\kappa}_{t}$.

To be able to make projections of mortality, only the time index $\hat{\kappa}_{t}$ needed to be projected since $\hat{a}_{x}$ and $\hat{b}_{x}$ are only dependent of age $x$-but not of time $t$. Following the standard time series methodology of Box-Jenkins we choose an ARIMA $(0,1,0)$ process, i.e. a random walk with drift, for $\left\{\hat{\kappa}_{t}\right\}_{t>0} .7$

By projecting the time series $\left\{\hat{\kappa}_{t}\right\}_{t>0}$, mortality rates for a person aged $x_{0}$ in year 0 can be forecast for future years $s=1,2, \ldots$ through

$$
\ln \hat{m}_{x_{0}+s, s}=\hat{a}_{x_{0}+s}+\hat{b}_{x_{0}+s} \hat{\kappa}_{s} .
$$

Central death rates $m_{x, t}$ are widely used by actuaries and even more so by demographers to describe and explain mortality, yet they are less illustrative than death or survival probabilities. Following the standard notation (see e.g. Bowers et al., 1997) we transformed the central death rate projections from (7) into survival functions. For a person aged $x_{0}$ at time 0 the survival function $s_{x_{0}}(s)={ }_{s} p_{x_{0}}$ gives the $s$-year survival probability $(s>0)$, the latter being the notation widely used by actuaries. It can be expressed as

$$
\begin{aligned}
{ }_{s} p_{x_{0}} & =\prod_{j=0}^{s-1} p_{x_{0}+j}=\prod_{j=0}^{s-1} 1-q_{x_{0}+j}=\prod_{j=0}^{s-1} 1-\left(1-\exp \left(-\mu_{x_{0}+j}\right)\right) \\
& =\prod_{j=0}^{s-1} \exp \left(-\mu_{x_{0}+j}\right)=\prod_{j=0}^{s-1} \exp \left(-m_{x_{0}+j, j}\right) \\
& =\prod_{j=0}^{s-1} \exp \left(-e^{\hat{a}_{x_{0}+j}+\hat{b}_{x_{0}+j} \cdot \hat{\kappa}_{j}}\right)
\end{aligned}
$$

For the transformations in (8) we use the frequently made assumption of constant force of mortality in each year, i.e. $\mu_{x, t+u}=\mu_{x, t} \quad \forall u \in[0,1)$, as well as the observation $q_{x, t}=1-e^{-\mu_{x, t}}$. See e.g. Bowers et al. (1997) for further details. Recall that we are only interested in mortality forecasts for a number of equally aged persons, or a single cohort for that matter. This implies that only one survival function $s_{x_{0}}(s) \quad \forall s=1,2, \ldots$ is necessary for our assessments which can be obtained by combining all survival probabilities ${ }_{s} p_{x_{0}}$ for $s=1,2, \ldots$.

Note that at this stage the survival function projections do not incorporate any randomness. To fill this gap, we recall that in the LC model or the PML approach the stochasticity of mortality rate projections arises exclusively from the time series $\left\{\hat{\kappa}_{t}\right\}_{t>0}$, and we determined this time-index to be an $\operatorname{ARIMA}(0,1,0)$ process, i.e. a random walk with drift. Formally we can express this time series as

$$
\hat{\kappa}_{t}=\hat{\kappa}_{t-1}+\theta+\eta_{t} .
$$

The drift parameter (or trend) $\theta$ is estimated from the fitted values of $\hat{\kappa}_{t}$. The disturbance terms $\eta_{t} \sim N\left(0, \sigma_{\kappa}^{2}\right)$, whose variance $\sigma_{\kappa}^{2}$ can also be estimated directly

\footnotetext{
${ }^{7}$ Although any $\operatorname{ARIMA}(p, d, q)$ model could have been used, the $\operatorname{ARIMA}(0,1,0)$ model has previously been determined by numerous authors for varying data sets.
} 
from fitted values of $\hat{\kappa}_{t}$, solely incorporate randomness. By transforming (9) we directly obtain randomized forecasts of the time-index when adding randomized values of $\eta_{t}$. Thus, combining (8) and (9) permits us to generate random realizations of the survival function $s_{x_{0}}(s)$.

While the presented PML approach extends the well-known LC model and thus overcomes some of the shortcomings of the original model, an important caveat must be made. As is the case with all attempts to model mortality, we do not know whether mortality actually behaves in the particular way assumed by LC and/or the PML approach. This uncertainty whether a chosen model is the correct model is commonly referred to as model uncertainty. Apart from this uncertainty, we also have to be aware of a number of shortcomings of the LC model that could not be corrected by the PML approach. To mention only some of these potential weaknesses, the LC model has been shown not to be able to sufficiently incorporate cohort effects $^{8}$; furthermore the LC model has been criticized for underestimating mortality risk in some situations.

In spite of these potential shortcomings we decided to retain the Lee-Carter model due to its widespread popularity as well as because of its tangibility. Nevertheless we admit that other models that have been proposed could possibly better capture some characteristics of mortality.

After having specified our asset and liability modelling approaches, and recurring to the blueprint of Dowd et al. (2006), we still need to provide a simulation framework and some risk measures. These ingredients will be presented next.

\section{The Simulation Framework}

In the previous section we described the underlying asset and liability model for an annuity provider. However, these models still need to be calibrated. Thus, in 3.1, we will describe the data and the calibration procedures. Consecutively, in order to simulate assets and liabilities simultaneously and thus obtain results that can further be analyzed, we will embed the underlying models in a simulation framework in 3.2 . As our objective is to analyze the risks within the annuity contracts, we introduce the considered risk measures in 3.3 .

\subsection{Data}

The evolution of the insurer's assets and liabilities depends on various quantities: Annuity prices, asset yields, survival probabilities, etc. In the following, we describe the data and the procedures used in order to derive these quantities. Since the annuities market in the UK is one of the largest markets we focus our analysis on data from the UK. In other annuity markets, e.g. in Germany, contracts are usually sold as participating contracts. Profit distribution forms a significant component and would have to be accounted for in those cases.

\section{Annuity Prices}

As a main objective of our investigation was to set up a realistic environment for the annuity provider considered, we needed to take market prices for the annuity

\footnotetext{
${ }^{8}$ For a detailed analysis of cohort effects in the UK, i.e. the effect that some cohorts participate more than others from lower mortality, cf. for instance Willets (2004). For an attempt to measure mortality improvements and compare cohort effects for a selection of countries see MacMinn et al. (2005).
} 
contracts considered. The Financial Services Authority (FSA), which is the regulatory body for - among others - insurance companies in the UK, regularly updates information concerning recent market prices for different types of annuity contracts in their comparative tables section on their web page. As mentioned earlier, we decided to consider prices for the open market options type of annuities, payable monthly in arrears and without any guarantees. Since mortality data of all data sets was available only until 2003, we decided to make our projections begin on January 1, 2004. We thus took the closest available prices, which are dated January 15, 2004. Among the 5 "cheapest" annuity providers, i.e. those providing the highest yearly (or monthly) payments for a fixed single premium, we chose the median provider to eliminate possible temporary effects of unusually "cheap" prices or high guaranteed rates.

\section{Bond Prices}

As our allocation strategies only allow for an investment into bonds at time 0 , we only need to know bond prices at the inception date, i.e. we can use historical data. We use UK government bonds ${ }^{9}$, where zero coupon yields are available for short term-, 5-year-, 10-year-, and 20-year bonds. For maturities in between, we interpolate linearly. As we also need bonds for longer maturities, we need to extrapolate the available data. Here, we took a conservative approach: If the yield curve was upward shaped, i.e. if the yields for bonds maturing in 20 years was higher than for bonds maturing in 10 years, we extrapolated the yield curve flat, that is we assumed that the yields for longer maturities equal that for a 20 -year bond. If the curve was downward shaped, we extrapolated linearly.

\section{Short rates and Stocks}

The short-rate model and the stock model are dynamic, i.e. we had to calibrate the parameters from Equations (3) and (4). For the interest rate model, we used maximum likelihood estimates (see e.g. Walter (1996)), and for the stock model we used the standard estimators for the logarithmic yields. As the amount of call money within an insurer's asset portfolio was rather slim, we used the 3-months LIBOR $^{10}$ from January 1978 to September 2006 (monthly data) for calibrating the short-rate model 11 For determining the parameters of the stock model, we used monthly time series of the FTSE 100 price index (January 1984 to September 2006) and of FTSE 100 dividend yields (September 2003 to September 2006). ${ }^{12}$

\begin{tabular}{|l|l|l|l|l|}
\hline stock model & $\mu$ & $\sigma_{S}$ & & \\
\hline & $12.07 \%$ & $16.20 \%$ & & \\
\hline short-rate model & $\kappa$ & $\gamma$ & $\sigma_{r}$ & $r_{0}$ \\
\hline & $5.54 \%$ & $8.04 \%$ & $5.2 \%$ & $3.99 \%$ \\
\hline
\end{tabular}

Table 1: Parameters of the asset models

In Table 1 , the resulting parameters are displayed $\sqrt{13}$ For the stock quota within the mixed portfolio, we used $37 \%$ as was displayed in the the LEGAL AND GENERAL PPFM Data Annex from 06/20/2006 for non-participating pension policies

\footnotetext{
${ }^{9}$ Source: http://www.statistics.gov.uk/statbase, 10/18/2006.

${ }^{10}$ London Interbank Offer Rate.

${ }^{11}$ Source: http://www.statistics.gov.uk/statbase, 10/18/2006.

${ }^{12}$ Source: http://www.statistics.gov.uk/statbase, 10/18/2006; due to data availability we used the shorter time series for the dividend yield .

${ }^{13}$ The parameter $\kappa$ relates to Equation (3).
} 
and adaptable pension plans. It is worth noting that within the second asset allocation strategy, where the majority of fund is invested in a bond portfolio, the proportion of stock within the insurers asset portfolio will be a lot smaller, as only $37 \%$ of the remaining funds are invested in stock.

\section{Mortality Data}

As a first step, we decided to consider three different sets of mortality data. On the one hand, we aimed at capturing typical mortality patterns of the UK population, on the other hand typical mortality of insured persons was of interest in the scope of the present investigation. As already mentioned, mortality rates of insured persons are in many cases substantially lower than those of the overall population. This is of course not due to the fact that insured persons have contracted with the insurance company, but that contraction is often preceded by thorough selection, i.e. the insurer tries to identify and reject persons with poor status of health. In the context of annuity contracts where a poor status of health potentially increases the risk of earlier than average time of death, this selection is obviously counterproductive. Thus a great scope for anti-selection is generated. However it is not of major interest in this investigation, and in the following we will focus on the effects of the varying mortality for people who actually hold an annuity policy.

We resorted to data from the Human Mortality Database (2006, henceforth HMD) for the overall population mortality, as it freely provides a large selection of demographic data series. Since data for the UK as a whole was not available we followed prior investigations and considered the series for male persons in England \& Wales. Data fitting was then performed with annual numbers of death and exposure to risk for ages 60-100 during calendar years 1983 through 2003.

Input for the modeling of mortality rates as described above was obtained from actual pensioners' mortality. This data was cordially provided by the Continuous Mortality Investigation Bureau (CMI), and we focused on observations from years 1983 to 2003 at ages between 60 and 100 in order to ensure compliance with the HMD data.

Apart from the usual per-capita data, i.e. exposures and deaths all having the same weight of 1 , we also considered mortality by amounts. This accounts for varying face values of annuity contracts, and it could possibly contribute to refine results with respect to (anti-)selection effects. Note that not only do insured persons exhibit lower mortality than the general population, but there is also evidence that persons with higher income - thus being able to buy annuity contracts with higher payments (and higher premiums) - tend to live longer than less well-off persons. We do not expect this refined distinction to contribute as much to the results as can be achieved by restricting computations to pensioners instead of the overall population, and we shall prove shortly.

At this point, an important remark concerning the term of the annuity contracts considered and the actual amount payable to the insured must be added. As all data sets which were taken into consideration provide only sparse data for ages beyond 100, or even report no deaths at these oldest ages in some calendar years, we renounced accounting for this data to avoid unreliable projections. Instead we assumed that if an insured person survived until just before his $101^{\text {st }}$ birthday the insurer would pay an unconditional compensation - regardless of the remaining life time of that individual. This can be regarded as a means to clear the portfolio of annuities and thus to dispose of the inherent uncertainty. If in reality an annuity provider should wish to pursue this strategy it might be next to impossible to find another insurance company which would accept this particular position since it 
poses heavy longevity risk, i.e. the risk of unusual long life time. Nevertheless this idea could be desirable for an insurer, and we expect the medium-term availability of such risk management tools.

Note that the expected remaining (curtate) life time $e^{14}$ beyond age 100, $\stackrel{\circ}{101}_{1 \infty}=$ $\stackrel{\circ}{101: \bar{~}}=\stackrel{\circ}{101}_{101}$ gives the expected number of future annuity payments - exactly those payments that will be paid for under the notion of a lump-sum compensation. To make the value of this compensation even more prudent no discounting was included so that for a face value (i.e. yearly payments) of 1 it simply amounts to $\dot{e}_{101}$.

For cohorts born in $z=1983-101=1882, \ldots, 2003-110=1893^{15}$, i.e. for those for which our data sets covered all ages beyond 100 , we determined $e_{101}(z)$. Since there was no significant trend across these cohorts, we took the average of observed cohorts' remaining life expectancy, $\stackrel{\bullet}{e}(z)$, to estimate the compensation. For each random path of mortality, given survival until age 101, this compensation was put up to close out the particular contract at that time, i.e. at time $t=z+101$.

\section{Fees and Expenses}

Annuities are subject to several fees and expenses. For example, for a typical contract of a large annuity provider, an initial expense of $200 £$ plus $1.3 \%$ of the premium paid, an investment fee of 7 basis points (bps), and an additional fixed annual renewing fee are representative. However, as the influence of the fixed fees, i.e. the $200 £$ initial expense and the annual renewing fee, depend on the annuity purchase price, we do not consider them for our analysis. Furthermore, we assume that there are no investment fees for the bond portfolio. Thus, we only consider an initial expense of $1.3 \%$ and an investment fee of $7 \mathrm{bps}$ for the risky portfolio.

\subsection{Combining Asset and Liability Simulations}

For both the mortality model and the development of the assets 20,000 random paths have been simulated. This was done in the following fashion:

- Parameters for both models were estimated from the underlying data sets.

- Random paths for the stock portfolio and the savings account were generated using the models from Section 2.2 using the previously estimated parameters.

- Estimated parameters from the PML approach were combined with the technique described in Equation (9) to obtain randomized survival probabilities.

- Asset and liability paths were combined to obtain 20,000 randomized developments of the annuity provider's portfolio.

This process was repeated in order to account for the different assumptions made: the two investment strategies presented in Subsection 2.2 and the different data sets of mortality.

\subsection{Measuring Risks}

Following the approach described in Subsection 2.1, $R_{t}$, the reserve per unit annuity at time $t, 16$ is intended to describe the financial situation of the annuity provider

\footnotetext{
${ }^{14}$ The curtate life expectancy gives the (integer) number of whole years a given individual will continue to live.

${ }^{15}$ Note that we interpret $\omega=110$ although the last class of ages in the HMD data denotes ages 110 and beyond. Due to very scarce data at this "age" we neglect possible inaccuracy.

${ }^{16}$ See (2) for the definition.
} 
considered. We recall that $R_{t}$ is a random variable since both the mortality development and the capital market situation are a priori unknown and can best be only roughly estimated or projected.

To gain an understanding of this random variable, we generated 20,000 possible realizations of these variables and aimed at assessing the risk or uncertainty as a whole. What was of even greater interest was the exact size of the mortality risk and the interest risk. Further details on our approach with respect to the latter objective will be given shortly.

Aggregating the remaining surplus values $R_{40}$ from all realizations of the models underlying the insurer's assets and liabilities allowed us to compute the expected value $\mathbb{E}\left(R_{40}\right)$, the shortfall probability $\mathbb{P}\left(R_{40}<0\right)$, the value at risk $(\mathrm{VaR})$ at probability level $\alpha$, i.e. $z_{\alpha}^{(40)}$ such that $\mathbb{P}\left(R_{40}<z_{\alpha}^{(40)}\right) \geq \alpha$, and the conditional tail expectation $\mathbb{E}\left(R_{40} \mid R_{40}<z_{\alpha}^{(40)}\right)$, assuming $\alpha=0.001$ in both cases. Furthermore, by plotting histograms of the realizations, we can derive empirical density functions.

The risk measures that have been defined above do at first relate to all random paths generated. Hence, they reflect random coincidences of a mortality development and an asset development. "Good" and "bad" developments - with respect to either part - can potentially balance. Insurers should tend to welcome this balancing of mortality and interest risk since they will in many cases benefit. However, this phenomenon might dilute the actual characteristics and it could also contribute to the faint interest in the magnitude of and the relationship between these two risks as was already described above.

In order to measure the magnitude of these two aspects of risk, we decided to condition the sampling described above on "good" and "bad" paths of mortality as well as of funds development. The exact interpretation and measurement of "good" and "bad" will be described after a sketch of our further proceeding. For the determination of "unidirectional conditional" risk measures, i.e. the risk measures described above restricted to "good" or "bad" random paths (with respect to either mortality or funds), we decided to combine a smaller number, e.g. 2,000, of the "best" and "worst" developments with respect to one component with a random selection of developments of the other component. In short: for the "conditional" risk measures with respect to mortality, we combined the 2,000 "best" mortality paths with 2,000 randomly chosen funds paths. The same was done with the 2,000 "worst" mortality paths. On the basis of these 2,000 reserve values $R_{t}$ the introduced risk measures were calculated.

It remains to specify how "good" and "bad" random paths were classified. This was done from the insurer's point of view, i.e. "good" mortality development basically translates into early death since in that case the obligation to pay terminates. "Good" developments with respect to funds refer to a high average or aggregate rate of return over time since higher yields are to be seen positive. "Bad" developments refer to the respective opposite interpretations.

To make exact comparisons between any two paths, we considered the 40-year life expectancy, $\stackrel{\Theta}{60: \overline{40}}$, for mortality paths and the aggregate interest rate development, $\sum_{k=1}^{40} f_{0, k}$ with $f_{0, k}=\prod_{t=1}^{k}\left(1+r_{t}\right)$, for the funds paths. While the former gives the expected number of years that a 60 -year person will continue to live within the next 40 years, the sum in the latter expression can be regarded as an approximation of the integral of the interest rate development curve. Since we are only considering discrete, i.e. quarterly or yearly interest rates, we resort to this Riemann-type approximation. Note that the exact values of these "measures" are irrelevant for our analysis, our comparisons are only based on the relative size of the numbers which we believe do adequately reflect the typical annuity providers' 
preferences in terms of (for the business) desirable mortality and interest rate realizations.

Applying these "measures" to the respective mortality paths permitted to compare and rank the random developments, and thus compute the "conditional" versions of the above risk measures, 17

\section{Results}

\subsection{Unconditional Analyses}

To analyze the risks inherent to the assumed annuity provider's business, we are going to focus on the risk measures previously defined under the various parameter settings detailed out in Subsection 3.2. Furthermore, as the expected value of the remaining surplus $\mathbb{E}\left[R_{40}\right]$ is in monetary units at time $t=40$, we also provide the discounted expected value $p(0,40) \mathbb{E}\left[R_{40}\right]$ which is given in monetary units at time $t=0$. However, as the return on a 40 -year bond in 2004 (4.24\% p.a.) is relatively low in comparison to the long term mean of interest rates, these quantities have to be interpreted with care, 18 Therefore, we include another "discounted" value $\tilde{p}(0,40) \mathbb{E}\left[R_{40}\right]$, where a hypothetical bond with an annual yield of $8 \%$ and price $\tilde{p}(0,40)$ is used.

First, when looking at the remaining surplus values after 40 years, $R_{40}$, we can identify a significant difference between considering the overall population or restricting our analysis to insured persons' mortality. The respective values for the bond-hedging strategy introduced as Strategy 2 are given in the second and fourth column of Table 2; Figure 1 shows the corresponding histograms.

\begin{tabular}{|l||l|l||l|l|}
\hline & Pop. Lives & & Ann. Lives & \\
\hline Risk Measures & Bond Based & Fund Based & Bond Based & Fund Based \\
\hline \hline $\mathbb{E}\left[R_{40}\right]$ & 98.45 & 201.53 & 47.35 & 176.39 \\
\hline$p(0,40) \mathbb{E}\left[R_{40}\right]$ & 17.92 & 36.69 & 8.62 & 32.12 \\
\hline$\tilde{p}(0,40) \mathbb{E}\left[R_{40}\right]$ & 4.19 & 8.59 & 2.02 & 7.52 \\
\hline $\mathbb{P}\left(R_{40}<0\right)$ & 0 & $0.11 \%$ & $0 \%$ & $0.76 \%$ \\
\hline$V @ R(0.001)$ & 14.36 & -9.45 & 6.8 & -22.40 \\
\hline $\mathbb{E}\left[R_{40} \mid R_{40}<V @ R\right]$ & 12.93 & -11.39 & 6.23 & -36.64 \\
\hline
\end{tabular}

Table 2: Risk measures for $R_{40}$, Population and Annuitants Lives

Under neither parameter constellation does $R_{40}$ become negative. Nevertheless the selection effect of assuming insured persons' mortality is obvious. The empirical distribution is somewhat closer to zero and it is less scattered than the overall population's surplus distribution. The expected value in the case of annuitants' mortality is roughly half what it were if general population mortality was considered. We can also observe a similar situation with the value at risk and the conditional tail expectation. This translates into the insurer operating under greater exposure to mortality risk, although we should underline the fact that at least the risk of shortfall, i.e. $R_{40}<0$, can be hedged under the assumption of Strategy 2.

The pronounced selection effect in the case of bond hedging can also be observed if the insurer does not try to hedge assets and liabilities, but instead pursues an

\footnotetext{
${ }^{17}$ The term "conditional" is not to be understood in a statistical sense, as e.g. the "conditional expectation". To make this distinction one could also resort to the term "filtered" or "limited" risk measures.

${ }^{18}$ For example, the mean reversion level of the CIR-process from equation (3) can serve as a proxy for the long term mean, and with $8.04 \%$ it is substantially higher than $4.24 \%$.
} 
"opportunistic" investment. In that case, however, shortfalls do occur, i.e. in some cases we observe $R_{40}<0$. As before, the insurers' surplus situation is somewhat tighter when resorting to annuitants' mortality while it is also less volatile compared to the general population case. Values of the considered risk measures are given in columns 3 and 5 of Table 2 .

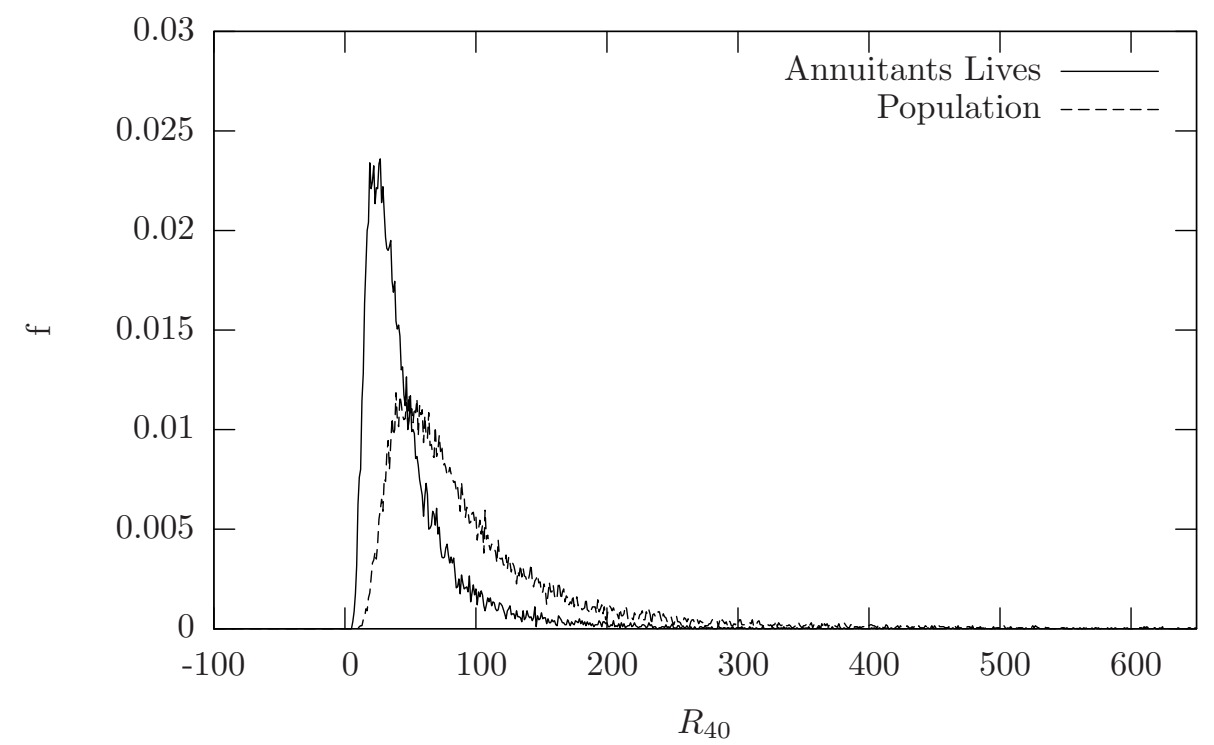

Figure 1: Histograms Bond Based Strategy

Figure 2 shows the simulated distributions of final reserves $R_{40}$ under both investment strategies when general population mortality is assumed. As pointed out before, no shortfalls occurred under the bond-hedging strategy but when opportunistic investment is assumed there are some cases in which $R_{40}<0$. While the expected final reserve under the opportunistic investment strategy is roughly twice what it is under Strategy 2, these potential insufficiencies produce a shortfall probability of $1.1 \%$. Also, both the V@R at 0.001 and the corresponding Conditional Tail Expectation become negative in the case of opportunistic investment while they remain positive under bond hedging, the values being listed in Table 2. This shows that the results are considerably more volatile if no bond hedging is available, rendering the final reserve situation less predictable.

The same tendencies can be observed when assessing the results in the situation of annuitants' mortality either with respect to lives or amounts, although the specific numbers differ from the case of the general population mortality. However, as a general result for our model we should emphasize that bond hedging prevents shortfalls regardless of the specific mortality data. Contrarily, under opportunistic investment $R_{40}<0$ does occur in all three cases, ranging from $1.1 \%$ with overall population mortality to $7.6 \%$ or $7.7 \%$ when incorporating the selection effects captured by annuitants' mortality.

A comparison of the results of the refined selection effect which becomes obvious when transiting from the usual concept of annuitant mortality, i.e. counting persons or lives, to insured amounts can be made with the values given in Table 3. Note that there is a selection effect not only when considering insured persons versus the overall population (as pointed out earlier), but one can also assume that people with higher "amounts", i.e. higher annuity payments, have been subject to even more prudent selection by the insurer. However, this selection effect is less pronounced 


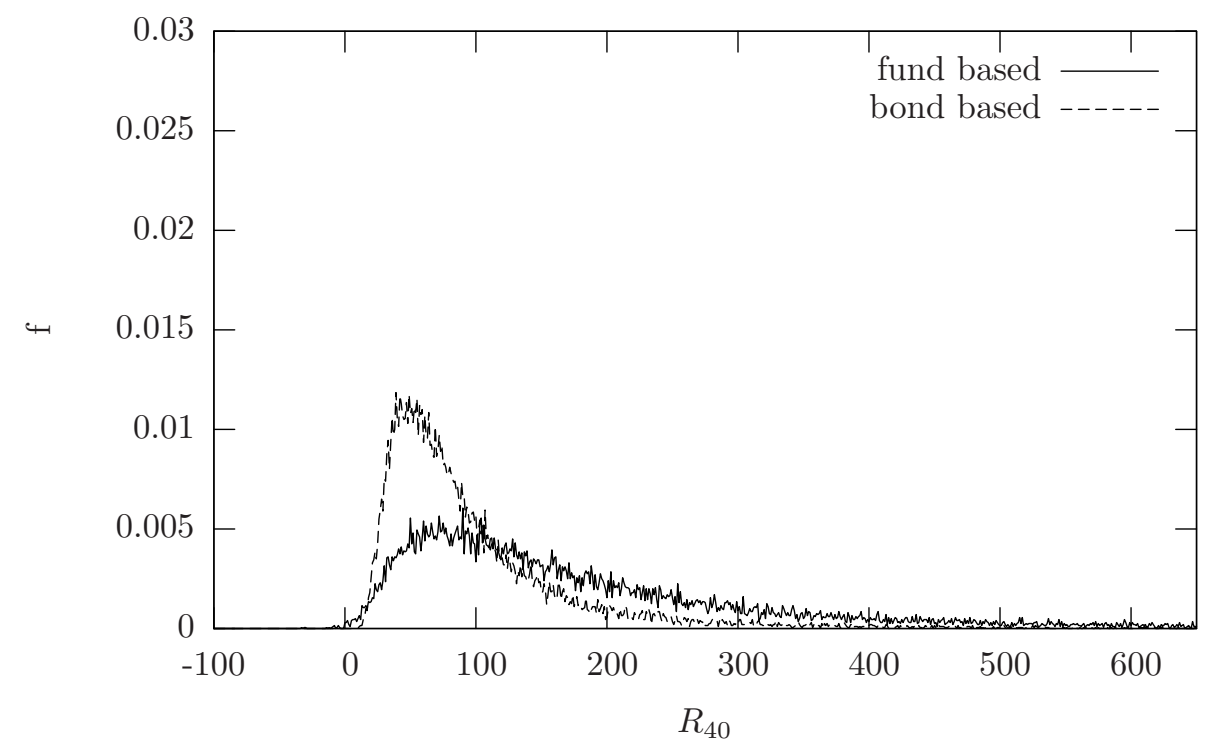

Figure 2: Histograms Population Lives

than the one described before. Looking at the specific numbers in Table 3 does not reveal more than minor but existing differences.

\begin{tabular}{|l||l|l||l|l|}
\hline & Ann. Lives & & Ann. Am. & \\
\hline Risk Measures & Bond Based & Fund Based & Bond Based & Fund Based \\
\hline \hline $\mathbb{E}\left[R_{40}\right]$ & 47.35 & 176.39 & 47.10 & 176.38 \\
\hline$p(0,40) \mathbb{E}\left[R_{40}\right]$ & 8.62 & 32.12 & 8.58 & 32.11 \\
\hline$\tilde{p}(0,40) \mathbb{E}\left[R_{40}\right]$ & 2.02 & 7.52 & 2.01 & 7.52 \\
\hline $\mathbb{P}\left(R_{40}<0\right)$ & 0 & $7.6 \%$ & 0 & $7.7 \%$ \\
\hline$V @ R(0.001)$ & 6.81 & -22.41 & 6.78 & -20.68 \\
\hline $\mathbb{E}\left[R_{40} \mid R_{40}<V @ R\right]$ & 6.23 & -36.64 & 6.26 & -36.35 \\
\hline
\end{tabular}

Table 3: Risk measures for $R_{40}$, Annuitants Lives and Amounts

While under the opportunistic investment strategy the results from the population mortality and the annuitants' mortality settings only differ slightly, which can been seen in Figures 2 and 3, respectively, greater differences can be seen in the case of the bond hedging strategy. For annuitants' mortality reserve values are less scattered, i.e. results closer to the expected final reserve $\mathbb{E}\left(R_{40}\right)$ occur more frequently than under the overall population mortality assumption. Even though no shortfalls were generated under these two settings the corresponding histograms show significant deviations. This is due to the cheaper set-up cost for the hedge portfolio for an annuitants portfolio sampled from the general population, which implies more funds are invested in risky assets.

To summarize the main results of the unconditional analysis, i.e. when randomly sampling from "good" and "bad" mortality and interest rate developments, observe that the bond hedging strategy 2 allows the insurer to completely dispel the risk of generating negative final reserves. Even if the opportunistic investment strategy is pursued, which was already pointed out to be a somewhat extreme assumption, shortfalls occurred relatively seldom with shortfall probabilities ranging between 


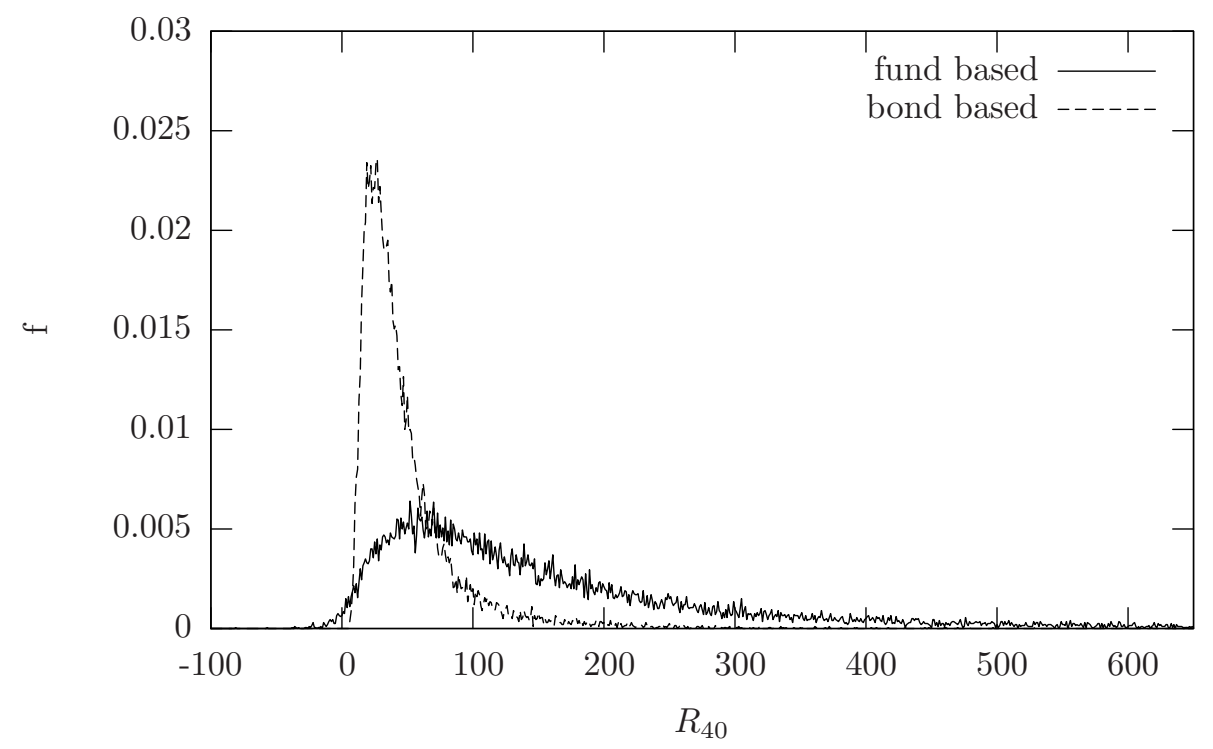

Figure 3: Histograms Annuitants Lives

roughly $1 \%$ and $8 \%$.

Two selection effects could be identified. The effect of transiting from the overall population to annuitants' mortality was larger than the further selection expressed by the transition from annuitants' lives to amounts which only marginally changed the results. However, the tendency is the same: the stronger the selection effect the less profitable was the annuity provider's situation after 40 years.

\subsection{Conditional Analyses}

The results from the preceding section were all based on the unconditional risk measures as introduced in Subsection 3.2 , i.e. they are based on random sampling of mortality and interest rate paths allowing "good" and "bad" developments to potentially balance. However, when arbitrarily combining only the $10 \%$ best or worst mortality paths with arbitrary interest rate developments, or vice versa, distinct observations can be made. The situation for results conditional on good and bad mortality or interest rate paths are given in Tables 4 and 5, respectively. Not only are the risk measures for the remaining surplus values $R_{40}$ given, but also reserve values for intermediate periods of 10 and 20 years.19 The conditional sampling results are presented together with results for the unconditional values, which have already been discussed in the previous section, in order to facilitate a comparison of both analyses.

As can be seen from Table 4, when restricting ourselves to good or bad mortality, these "marginal" results are relatively close to those from the unconditional analysis. Figure 4 shows the corresponding histograms, and although differences are not strikingly pronounced significant differences between the "bad" and "good" results can be seen, though. A spread of almost 5 per unit means that the annuity could potentially be paid for five more years. If the difference between actual and actuarial

\footnotetext{
${ }^{19}$ Note that a direct comparison of these intermediate values with "final" values $R_{40}$ is not possible when analyzing results under bond hedging, since the investment strategy is adapted to the annuity term of 40 years. After only 10 or 20 years, the majority of bond payments have not yet been obtained, thus these amounts are not reflected in the values expressed by $R_{10}$ or $R_{20}$.
} 


\begin{tabular}{|l|l|l|l|}
\hline & Bad Mortality & Unconditional & Good Mortality \\
\hline \hline $\mathbb{E}\left[\tilde{R}_{10}\right]$ & 3.02 & 3.07 & 3.09 \\
\hline Rel. Deviation & $-1.44 \%$ & 0 & $+0.81 \%$ \\
\hline \hline $\mathbb{E}\left[\tilde{R}_{20}\right]$ & 6.9 & 7.16 & 7.29 \\
\hline Rel. Deviation & $-3.66 \%$ & 0 & $+1.87 \%$ \\
\hline \hline $\mathbb{E}\left[\tilde{R}_{40}\right]$ & 43.82 & 47.35 & 49.08 \\
\hline Rel. Deviation & $-7.46 \%$ & 0 & $+3.64 \%$ \\
\hline$p(0,40) \mathbb{E}\left[R_{40}\right]$ & 7.98 & 8.62 & 8.94 \\
\hline$\tilde{p}(0,40) \mathbb{E}\left[R_{40}\right]$ & 1.87 & 2.02 & 2.1 \\
\hline
\end{tabular}

Table 4: Expected values of the free reserve, conditional on mortality and unconditional, using annuitants' lives mortality, bond-based strategy

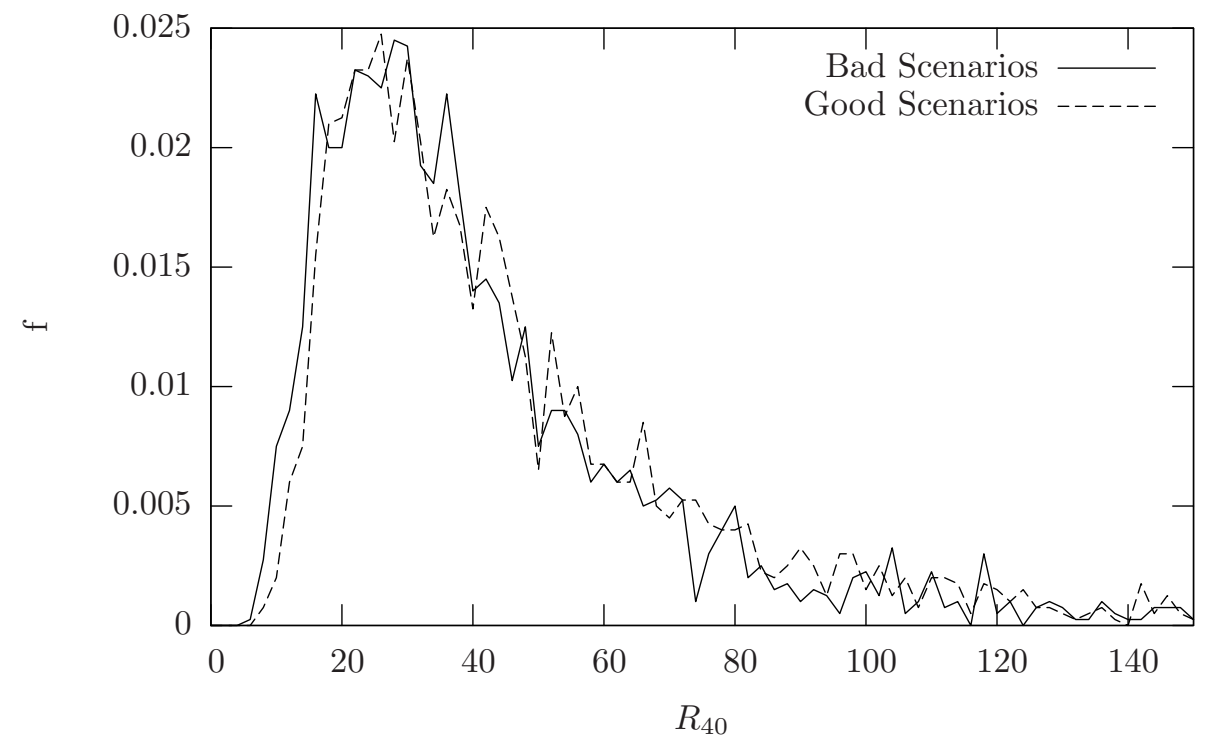

Figure 4: Comparison of influence of good and bad mortality

fair price, i.e. the "transaction cost", was smaller the situation would be drastically different for the annuity provider. In short: there is significant risk, but due to relatively high transaction costs, is not visible in our results to that extent.

When compared by the time horizons of 10,20 , and 40 years we can see that the overall tendency is similar in all three cases, but the relative deviations of bad/good cases versus the unconditional results, or the spread between the results conditional on bad and good developments increase with the respective period. In the case of "marginal" or extreme bad and good mortality scenarios (cf. Table 4), these spreads amount to between $-1.44 \%$ to $+0.81 \%$ after 10 years while they increase over time to $-7.46 \%$ and $+3.64 \%$ after 40 years, respectively. However, these values should be interpreted with care; as outlined above the investment strategy does not account the shorter periods of 10 or 20 years. As was already shown by a number of authors, uncertainty about changes in mortality grows with the period considered. This has often been visualized by widening confidence intervals for mortality projections. While during the first years only relatively low uncertainty influences projections, 


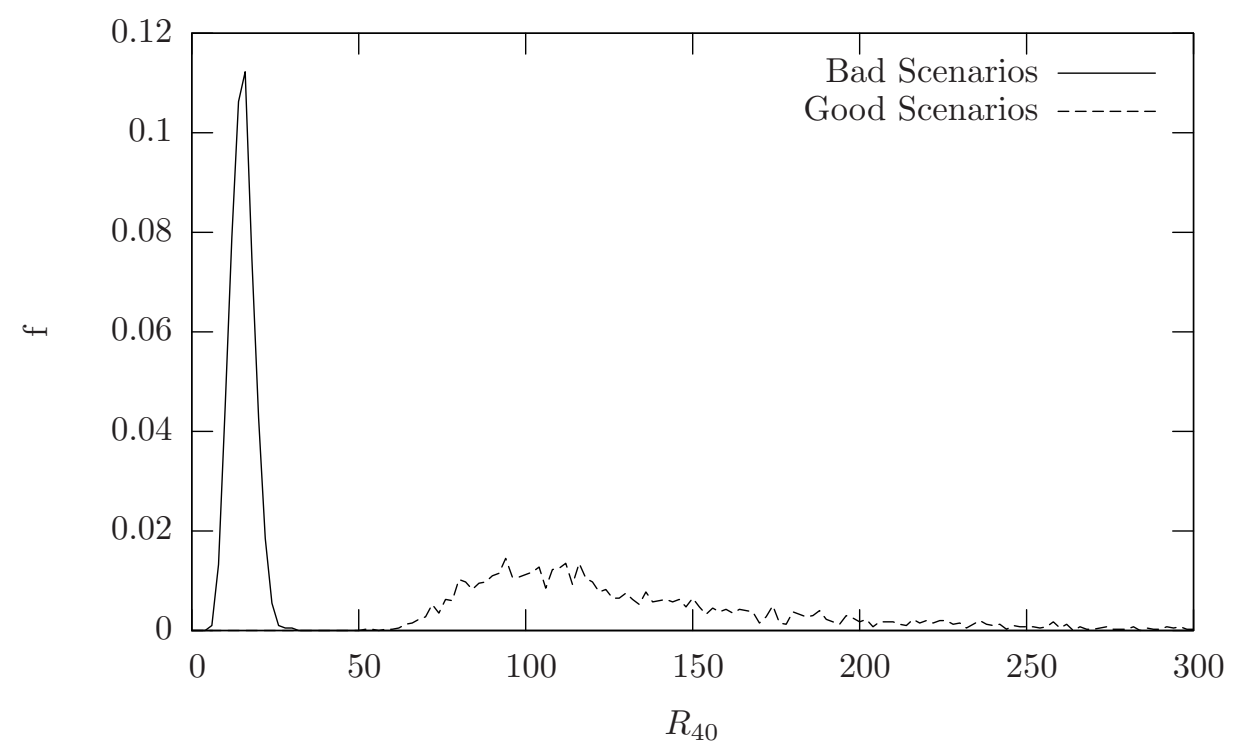

Figure 5: Comparison of influence of good and bad capital market developments

the situation is considerably different when analyzing results for longer terms especially for terms in the range of 40 years. Having this fact in mind, a smaller "transaction cost" could be considered equally sufficient for early contract years since later on compound interest effects become available and can thus possibly balance uncertainty.

\begin{tabular}{|l|l|l|l|}
\hline & Bad Interest Rates & Unconditional & Good Interest Rates \\
\hline \hline $\mathbb{E}\left[\tilde{R}_{10}\right]$ & 2.41 & 3.07 & 3.73 \\
\hline Rel. Deviation & $-21.35 \%$ & 0 & $+21.76 \%$ \\
\hline \hline $\mathbb{E}\left[\tilde{R}_{20}\right]$ & 4.02 & 7.16 & 12.17 \\
\hline Rel. Deviation & $-43.89 \%$ & 0 & $+70.00 \%$ \\
\hline \hline $\mathbb{E}\left[\tilde{R}_{40}\right]$ & 14.16 & 47.35 & 140.45 \\
\hline Rel. Deviation & $-70.11 \%$ & 0 & $+196.59 \%$ \\
\hline$p(0,40) \mathbb{E}\left[R_{40}\right]$ & 2.58 & 8.62 & 25.57 \\
\hline$\tilde{p}(0,40) \mathbb{E}\left[R_{40}\right]$ & 0.60 & 2.02 & 5.99 \\
\hline
\end{tabular}

Table 5: Expected values of the free reserve, conditional on interest rates and unconditional, using annuitants' lives mortality

If we change the perspective and analyze the values given in Table 5, i.e. results conditional on bad and good interest rate developments, we observe that these marginal values cover larger intervals with respect to all three time horizons.

From Figure 5 it becomes obvious that good and bad scenarios with respect to the capital market produce significant differences. On the one hand "bad" results are closer to values of zero than the "good" ones, which was to be expected, but since we assumed the more realistic bond hedging strategy as well as annuitants' mortality in order to be closer to the situation of an annuity provider none of the sampling results produced negative reserves - neither final values $R_{40}$ nor intermediate. On 
the other hand, "bad" capital market development lead to results that are far less volatile, i.e. possible values are significantly more concentrated on a relatively small interval ranging from zero to approximately 35 . This may be surprising when compared to the results we obtain when limiting our considerations to the $10 \%$ "best" capital market paths, in which final reserve values are generally larger, but are also spread over a much larger interval. In that case the major portion of values lie somewhere in the interval between 50 and 300. Although the variation of results is somewhat opposite to what "bad" and "good" capital market paths would suggest, they do not lead to significant risk when thinking of shortfalls, i.e. $R_{40}<0$. They rather pose risk to the annuity provider in the sense that the influence of mortality and the remaining variation among the "good" paths make projections about specific levels of reserves and thus surplus considerably uncertain.

The observations so far are in good consonance with the frequently assumed statement that mortality risk in annuities is a lot smaller than the risk arising from the capital markets. However, one should note that interest rate risk can be hedged, which can be seen when comparing the bond hedging strategy with the opportunistic investment. While the latter is a situation where the insurer is completely exposed to interest rate risk, investment strategy 2 tries to hedge that risk by investing in a bundle of bonds in advance.

Although fluctuations generated by unforeseen mortality paths tend to be considerably smaller they can still be of great interest for an annuity provider since mortality risk cannot yet be hedged with appropriate instruments on the market. Hence mortality fluctuations - despite their smaller influence on the aggregate risk as outlined before - may pose a greater problem for annuity providers.

What can also be observed is that fact that the longer the time horizon the more pronounced become the influence of bad or good mortality and interest rate scenarios.

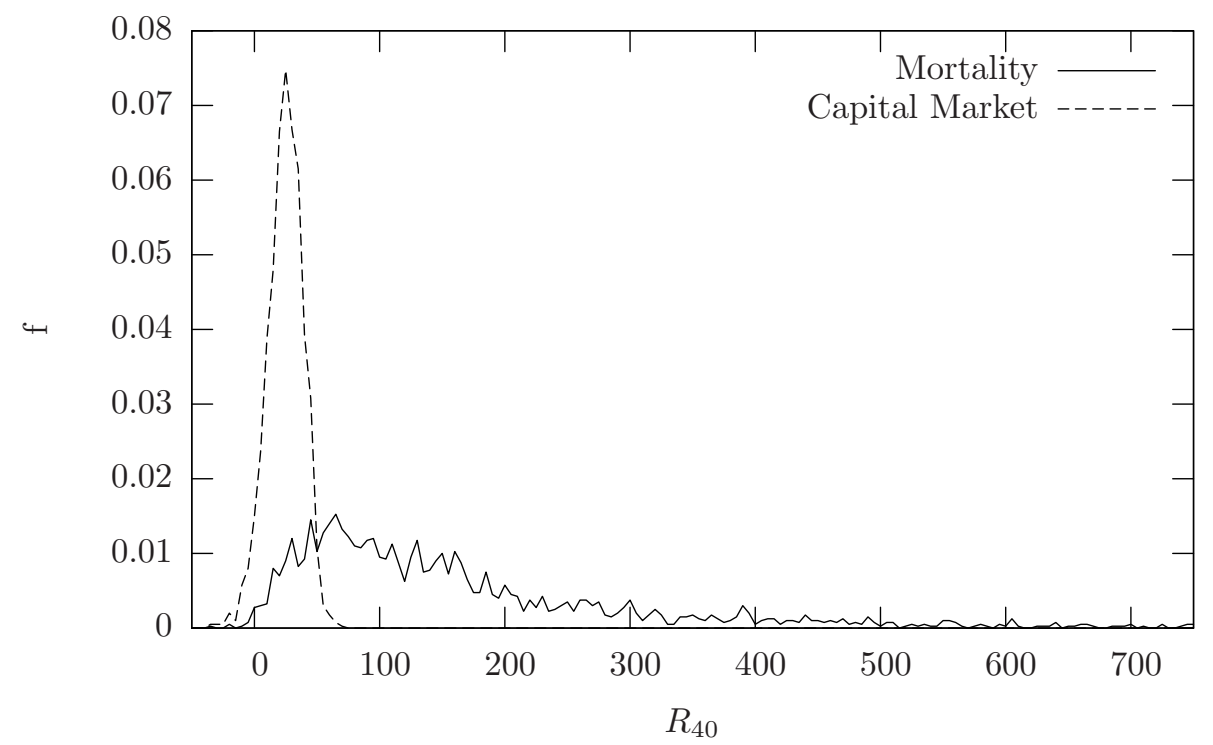

Figure 6: Comparison of influence of bad scenarios, fund based

To underline our caveat regarding the hedgeability of capital market risks, consider a hypothetical situation where no hedging by buying appropiately composed bundles of bonds. Figure 6 then contrasts the results for final reserves $R_{40}$, assuming - as before - mortality of insured persons, conditional on both "bad" mortality 
paths and "bad" capital market developments. While both situations may lead to negative final reserves, the risk of shortfall is far greater when capital markets develop undesirably as compared to the situation when mortality turns out to be extremely "bad" from the insurer's point of view.

Again one peculiarity can be identified. Similar to the observation made before, we see that bad capital market scenarios lead to considerable shortfall probabilities but produce results for the final reserves that only scarcely exceed 100, while on the other hand bad mortality scenarios pose a smaller shortfall risk, but generate surplus values anywhere in the range of between -50 and +750 . Again, "risk" of bad mortality developments mainly arises not from possible shortfalls but rather from the uncertainty about which specific value the final reserves will have.

\section{Conclusions}

In the last section, we analyzed the risks within a book of annuities. One of the key findings is that under almost all circumstances, the annuity provider will be able to meet his obligations. Even under a very opportunistic asset allocation strategy, conditional on a (from the insurer's perspective) negative evolution of the mortality, i.e. if people tend to live extremely long, and under a very disadvantageous evolution of the financial market, the shortfall probability, that is the probability that the insurer cannot fulfill his obligations, is very low. This is mainly due to the considerable contingency funds. Under the bond strategy, where the insurer tries to hedge his position as well as possible at time zero, the cost of this hedge actually is the actuarially fair annuity price as defined by Mitchell et al. (1999) and Finkelstein and Poterba (2002). In the UK during the late 1990s, the latter find that for an annuitant, i.e. with selection effects taken into account, the money's worth of an annuity amounts to between 86 and 95 pence per pound annuity. For 2004 and the specific annuity product we consider in this paper, we observe a discount of 13.45 percent, i.e. the money's worth amounts to 0.8655 per unit annuity, which is at the upper end of the spectrum from Finkelstein and Poterba (2002).

Thus, our results indicate that - under our assumption - this remaining difference between actual and actuarially fair annuity price, which can be considered to describe a transaction cost, is sufficient to sustain even very disadvantageous scenarios with a profit. But can the whole costs be used to fulfill the insurer's obligations if necessary? Or, are there other cash flows that need to be included? According to Mitchell et al. (1999) and Friedmann and Warshawsky (1990), this transaction cost it is mainly due to expenses, profit margins, and contingency funds. However, Milevsky and Young (2007) point out that for variable-payment annuities there is a explicit mortality risk fee. They believe that while some economists might classify any additional fee as transaction costs, this particular fee is an inseparable component of aggregate mortality risk and creates a unique impediment to annuitization. As there must be similar fees within fixed annuities, a substantial part of the costs assessed in the present paper will also be a mortality risk fee.

Under this assumption, however, the question arises whether this fee is adequate. And here, our simulation study suggests that it is not. In fact, the transaction cost proves to be sufficient to cover the insurer's obligations in almost all cases, even under risky allocations where huge profits are possible (see Table 2).

Moreover, our conditional analyses show that mortality risk is far less influential than financial risk. However, the latter - at least for the most part - is hedgeable. The fact that the shape of the distribution of the remaining surplus is still more influenced by the financial risk even under this hedge, i.e. under the bond-based strategy, is also due to the high level of transaction cost: After the hedge portfolio is set up, the difference between actual and fair value is invested in the fund and 
therefore, the performance of the insurer's asset portfolio is still highly dependent on the performance of the financial market.

As shown by Davidoff et al. (2005), full or at least partial annuitization remains optimal in many situations, even when annuities are not actuarially fair. Thus, our results are certainly not able to explain the annuity puzzle. However, they may give rise to one possible solution: An increase in the loading leads to a proportional drop in annuity payments for a given annuity premium, which, ceteris paribus, makes the annuity - as an investment opportunity from the retiree's perspective - less attractive. This leads to a shrinking annuity demand (see Mitchell et al. (1999) or Schulze and Post (2006)), and this means that a decrease in the loading will lead to an increasing annuity demand. But how could the price difference be reduced?

As pointed out by Dowd et al. (2006), insurance companies seem to have a general problem with assessing the magnitude of the financial risk implied by their mortality exposure. However, with the increasing number of models and contributions of how to assess and manage aggregate mortality risk, insurers will become more familiar with this risk. ${ }^{20}$ As a consequence of this education, it is rather likely that insurers will dare to offer annuities cheaper in the future.

One promising way to manage longevity risk is securitization via so-called mortality derivatives, for example longevity bonds, which have been the subject of lively discussions in the actuarial community in the recent past (see, e.g., Blake et al. (2006) and references therein). The basic idea of a longevity bond is that the coupon payments depend on the proportion of survivors of a certain cohort or population. Thus, if properly designed, these instruments could help annuity providers hedge most of their aggregate mortality risk while the other end of the risk could be taken by the market. And as these are investment opportunities with a rather low correlation to "regular" asset classes, the market's appetite could be considerable while the hedge for the insurer's could be relatively cheap.

\section{Summary, Limitations and Outlook}

This paper presents an analysis of the risks within a book of single premium immediate annuities. We use historical prices of annuities from the UK and simulate the insurer's assets and liabilities simultaneously. For the simulation, stochastic models for assets and liabilities are needed; we decided to use well-known and well-studied, but rather simple models, and calibrate them to UK financial and mortality data, respectively. In order to simulate the assets, we have to assume asset allocation strategies for the annuity provider. We introduce two very simple, but yet extreme strategies: In the first strategy, the insurer does not try to hedge the liabilities and invests the complete reserve in a fund consisting of a risky and a locally risk-free asset (bank account) at constant proportions, whereas in the second strategy, the insurer tries to hedge liabilities as well as possible, seen from the inception date, by buying zero-coupon bonds to cover expected payoffs in each year.

By Monte-Carlo simulations, we derive the distribution of the remaining per contract surplus for an annuity paying one unit each year after the portfolio has run off, that is, after all the annuitants within the insurers portfolio have deceased. Aside from providing plots of the density functions of the remaining surplus for the different allocation strategies and different underlying data sets, we compute several risk measures to characterize the risk-return profile of the insurer's position.

Our results indicate that the insurer's position is not very risky at all. Even under the rather opportunistic first allocation strategy, the shortfall probability, i.e. the probability that the insurer will not be able to fulfill obligations, is $0.1 \%$, and the

\footnotetext{
${ }^{20}$ For example, the last issue of The Journal of Risk and Insurance in 2006 was completely dedicated to longevity risk.
} 
expected discounted surplus is more than 36 units, i.e. more than twice the initial price of the annuity, if we calibrate the mortality model to the general population. If we use annuitants' mortality data, the situation changes tremendously: With $0.76 \%$, the shortfall probability is almost seven times as high, and the expected discounted surplus is decreased by more than $12 \%$ to approximately 32 units. Thus, our results are in line with earlier contributions who found pronounced selection effects within annuities, ${ }^{21}$ However, the shortfall probability is still very low and the expected surplus is still very high. Contrarily, if we consider the more conservative bond-based strategy, no shortfalls occur at all. Therefore, the "transaction cost" within the annuity's premium seems to be more than sufficient to cover the insurer's obligations, even under rather disadvantageous scenarios.

In order to compare the influence of the aggregate mortality risk and the financial risk within the annuity book, we present a series of conditional analyses: By restricting our simulation to (from the insurer's perspective) advantageous or disadvantageous mortality and financial scenarios, respectively, we are able to assess how "bad" or "good" mortality or financial environments affect the insurer.

We find that the performance of the financial market is far more influential for the distribution of the remaining surplus than the evolution of mortality improvements. However, at least within the bond-based strategy, this is mainly due to the enormous safety loading as it is invested in the rather risky fund. This is also the reason why the distribution of the remaining surplus for the bond-based strategy is altered considerably when switching from financially beneficial evolutions to nonbeneficial evolutions and vice versa. However, for the bond-based strategy there are still no shortfalls for bad capital market evolutions as the "necessary part" of the interest rate risk is hedged by the bond portfolio. While an advantageous or a disadvantageous evolution of mortality improvements is clearly noticeable in the distribution, the influence is far less pronounced. The difference in the discounted expected value of the remaining surplus for "good" and "bad" scenarios amounts to less than one unit. Thus, a safety loading which is considerably smaller than the "transaction cost" found in the insurance premium would be sufficient.

Under the assumption that a considerable part of this "transaction cost" is a premium for aggregate mortality risk, we conclude that insurers charge too much for it. If insurers were to charge less, i.e. if they offered annuities at a lower price, the annuity demand would be stimulated, and this would at least partly alleviate the annuity puzzle. The fact that insurers charge too much could be explained by the general problem insurance companies seem to have with assessing the magnitude of the financial risk implied by their mortality exposure. ${ }^{22}$ However, with an increasing number of contributions from the recent past regarding aggregate mortality risk, we believe that annuity providers will become more familiar with assessing and managing their longevity risk, which could lead to "more fair" annuity prices. For example, one promising way to manage longevity risk could be the introduction of so-called longevity bonds ${ }^{23}$ to the market, enabling insurers to hedge most of their aggregate mortality risk at a relatively low cost.

Even though our results are rather strong, it would not be appropriate to rely on them without further research. In particular, with regard to the underlying models for the assets and liabilities as well as their parameterizations, caution is required.

For modeling the risky asset portfolio, we used a geometric Brownian motion. While this model is still the market standard, several empirical studies have shown that it has considerable weaknesses. For example, Schoutens (2002) shows that there are limitations regarding the distributional properties of the Brownian motion

\footnotetext{
${ }^{21}$ See, for example, Finkelstein and Poterba (2002) or Mitchell et al. (1999).

${ }^{22}$ See Dowd et al. (2006).

${ }^{23}$ See, e.g., Blake et al. (2006).
} 
for modeling asset processes. Also, the one factor CIR model, which we used for modeling the short rate process, has been criticized for modeling interest rates over long periods due to its limited variation in the long run. Moreover, the assumptions of independence between assets and interest rates and, as already critically discussed in Section 2.2, the existence of ultra long bonds have to be scrutinized.

As pointed out in Section 2.3, the PML/LC approach for modeling the evolution of mortality has some shortcomings, too. Aside from the common problem of model uncertainty, there are also several specific shortcomings. For example, the PML/LC model has been criticized for underestimating mortality risk in some situations which could be particularly problematic for our risk analysis. Moreover, we did not incorporate parameter uncertainty in our models, which could also lead to an underestimation of the risk.

Another critical point is the fact that we restricted our analysis to the influence of aggregate mortality risk but ignored the influence of unsystematic mortality risk arising due to the finite number of annuitants within an insurer's portfolio. Also, there are open issues regarding costs and fees within annuity products, meaning our assumption that the "transaction cost", i.e. the positive difference between the actual and the actuarially fair price, can solely be interpreted as a premium for aggregate mortality risk is questionable.

Due to all these possible pitfalls, our findings and conclusions need to be interpreted carefully. More specifically, the quantitative outcomes need to be handled with care. However, regarding the qualitative implications, we consider the strength of our results as a clear indication that annuities currently offered may be overpriced.

In order to underline this hypothesis, it is necessary to check the robustness of our findings with regard to other asset and liability models. Thus, the next steps will include the incorporation of other, more advanced models for the underlying assets and the evolution of mortality into our framework. Furthermore, extending our framework to include unsystematic mortality risk may be worthwhile.

In addition to improving the technical characteristics of our framework, the economic assumptions need to be scrutinized. In particular, a detailed study and dissection of the "transaction cost" within annuities could help to better understand annuity products in general.

In spite of these problems and open issues, we believe that our study offers a valid approach to the assessment of the risk within annuity products and provides insights to the composure of the risk faced by annuity providers. While our key finding that the fee charged for aggregate mortality risk is very large relative to the risk's influence needs to be confirmed in future studies, which is due to uncertainties regarding the models and parameters used, we believe that it could have implications for the annuity and other puzzles.

\section{References}

Alho, J.M., 2000. Discussion of Lee (2000). North American Actuarial Journal, 4:91-93.

Biffis, E., Denuit, M., Devolder, P., 2005. Stochastic Mortality Under Measure Change. Working Paper, Cass Business School and Université Catholique de Louvain.

Bingham, N., Kiesel, R., 2003. Risk-Neutral Valuation. Springer Finance, Springer, Berlin. 
Blake, D., Cairns, A.J., Dowd, K., MacMinn, R., 2006. Longevity Bonds: Financial Engineering, Valuation and Hedging. The Journal of Risk and Insurance, 73:647672 .

Bowers, N.L., Gerber, H.U., Hickman, J.C., Jones, D.A., Nesbitt, C.J., 1997. Actuarial Mathematics. The Society of Actuaries, Schaumburg, Illinois, USA.

Brillinger, D.R., 1986. The natural variability of vital rates and associated statistics. Biometrics, 42:693-734.

Brouhns, N., Denuit, M., Vermunt, J.K., 2002. A Poisson log-bilinear regression approach to the construction of projected lifetables. Insurance: Mathematics and Economics, 31:373-393.

Brown, J.R., 2001. Private pensions, mortality risk, and the decision to annuitize. Journal of Publc Economics, 82:29-62.

Cairns, A.J., Blake, D., Dowd, K., 2006a. Pricing Death: Frameworks for the Valuation and Securitization of Mortality Risk. ASTIN Bulletin, 36:79-120.

Cairns, A.J., Blake, D., Dowd, K., 2006b. A Two-Factor Model for Stochastic Mortality with Parameter Uncertainty. The Journal of Risk and Insurance, 73:687718.

Cox, J.C., Ingersoll, J.E., Ross, S.A., 1985. A Theory of the Term Structure of Interest Rates. Econometrica, 53:385-407.

Currie, I.D., Durban, M., Eilers, P.H.C, 2004. Smoothing and forecasting mortality rates. Statistical Modelling, 4:279-298.

Davidoff, T., Brown, J.R., Diamond, P.A., 2005. Annuities and Individual Welfare. The American Economic Review, 95:1573-1590.

Dowd, K., Cairns, A.J., Blake, D., 2006. Mortality-dependent financial risk measures. Insurance: Mathematics and Economics, 38: 427 - 220.

Finkelstein, A., Poterba, J., 2002. Selection Effects in the Market for Individual Annuities: New Evidence from the United Kingdom. Economic Journal, 112:2850 .

Friedmann, B.M., Warshawsky, M.J., 1990. The Cost of Annuities: Implications for Saving Bahavior and Bequests. The Quarterly Journal of Economics, 105: $135-154$

Goodman, L.A., 1979. Simple models for the analysis of association in crossclassifications having ordered categories. Journal of the American Statistical Association, 74:537-552.

Human Mortality Database, 2006. University of California, Berkeley (USA) and Max-Planck-Institute for Demographic Research, Rostock (Germany). Retrieved October 20, 2006 from http://www.mortality.org.

James, E., Song, X., 2001. Annuity markets around the world: money's worth and risk internediation. CeRP Working Paper 16/01.

Lee, R.D., Carter, L.R., 1992. Modeling and forecasting US mortality. Journal of the American Statistical Association, 87:659-675.

Lee, R.D., 2000. The Lee-Carter Method For Forecasting Mortality, with Various Extensions and Applications. North American Actuarial Journal, 4: 80-91. 
MacMinn, R.D., Ostaszewski, K., Thiagarajah, R., Weber, F., 2005. An Investigation of Select Birth Cohorts. in: Living to 100 and Beyond, Society of Actuaries Monograph, Schaumburg, Illinois.

Milevsky, M.A., Moore, K.S., Young, V.R., 2006. Asset Allocation and AnnuityPurchase Strategies to Minimize the Probability of Financial Ruin. Mathematical Finance, 16: 647-671.

Milevsky, M.A., Young, V.R., 2007. The timing of annuitization: Investment dominance and mortality risk. Insurance: Mathematics and Economics, 40 :134-144.

Mitchell, O.S., Poterba, J.M., Warshawsky, M.J., Brown, J.R., 1999. New evidence on the money's worth of individual annuities. American Economic Review, 89:1299-1318.

Murthi, M., Orszag, J.M., Orszag, P.R. , 1999. The Value for Money of Annuities in the UK: Theory, Experience and Policy. Working Paper, Birkbeck College, London.

Renshaw, A.E., Haberman, S. , 2003. Lee-Carter mortality forecasting with agespecific enhancement. Insurance: Mathematics and Economics, 33:255-272.

Schoutens, W., 2003. Lévy Processes in Finance: Pricing Financial Derivatives. Wiley.

Schulze, R.N., Post, T., 2006. Transferring the Sticky: Individual Annuity Demand and Demographic Risk. Working Paper, Humboldt Universität zu Berlin.

Tuljapurkar, S., Nan, L., Boe, C., 2000. A universal pattern of mortality decline in the G7 countries. Nature, 405:789-792.

Van de Ven, J., Weale, M., 2006. A General Equilibrium Analysis of Annuity Rates in the Presence of Aggregate Mortality Risk. National Institute Discussion Paper 282 .

Walter, U., 1996. Die Bewertung von Zinsoptionen. Gabler Verlag, Wiesbaden, Germany.

Willets, R.C., 2004. The Cohort Effect: Insights and Explanations. British Actuarial Journal, 10(4): $833-877$.

Yaari, M., 1965. Uncertain Life-time, Life Insurance and the Theory of the Consumer. Review of Economic Studies, 32: 137 - 150. 